\title{
Life of coal mine planning - engaging in land use planning at Luscar and Gregg River mines
}

\author{
S. Karmacharya Alberta Sustainable Resource Development, Canada
}

M. Symbaluk Teck Resources Ltd., Canada

D. Brand Coal Valley Resources Inc., Canada

S. Schwartz Alberta Sustainable Resource Development, Canada

\begin{abstract}
Luscar Mine and Gregg River Mine lease areas are located along the front range of the Rocky Mountains, adjacent to Jasper National Park, Canada. The active mining area has been reclaimed resulting in the reestablishment of the area as part of the home range of wildlife species, including bighorn sheep, elk and provincially threatened species such as grizzly bear and Athabasca rainbow trout. In addition to these prominent species, significant wildife diversity has emerged and continues to evolve.
\end{abstract}

The Luscar and Gregg River Mines Land Management Plan Working Group was formed to develop a land management plan and consists of membership from Alberta Sustainable Resource Development (ASRD), Teck Resources Ltd., Coal Valley Resources Inc., Alberta Environment and Yellowhead County.

The methodology employed for land management planning involved communities, interest groups and the public. The process engaged stakeholders representing a variety of community interests. The process established a vision for the area that would allow for management of the reclaimed habitat and re-colonising populations of wildlife along with reasonable and appropriate human use, thus providing opportunities for interpretation, education, recreation and ecotourism.

The process provided an opportunity for collaboration among provincial and local government, industry, stakeholders and the public to explore a more strategic and integrated land management approach to endland-use planning.

\section{Introduction}

The landscape in Alberta, Canada is increasingly busy with a variety of competing demands. This encourages innovative end-land-use planning approaches including engagement with stakeholders, industry and government to appropriately address land stewardship in a way that considers future values and use.

The coal mines in the area operate with provincial permits awarded by the Energy Resource Conservation Board (ERCB) under the Coal Conservation Act. Licenses specific to each mine pit are also issued by the Energy Resources Conservation Board in coordination with Alberta Environment's (AENV) approval process. Reclamation is primarily regulated under the Environmental Protection and Enhancement Act (EPEA) administered by AENV, and the Public Lands Act administered by Alberta Sustainable Resource Development (ASRD). Through the EPEA approvals, Government of Alberta (GOA) regulates air, water, waste, land conservation and reclamation, fish, wildlife and biodiversity. Approval from ASRD provides access to the land through a Mineral Surface Lease (MSL) issued under the Public Lands Act. The Energy Resources Conservation Board regulates mine development including landform design and tailings management. The federal Department of Fisheries and Oceans (DFO) provides authorisations where required (e.g. habitat alteration).

Sub-surface coal mining in the area began in 1911. Modern open pit mining in the Luscar and Gregg River mines area started in 1969 to supply coal for overseas markets. The planning area encompasses a significant contiguous area of mine lands of over 7,100 hectares within which over 3,300 hectares was disturbed. Currently, the tenure of these lands assures wildlife protection through limited and controlled public access due to MSL tenure and post mining reclamation. To date, reclamation of about 100 per cent of the Gregg 
River Mine and about 50 per cent of the Luscar Mine's disturbed area has been completed (earthworks and initial revegetation completed, forest establishment in progress) and reclamation is on-going on the remaining areas of disturbance (Luscar and Gregg, 2011).

To date, the main foci of the reclamation plans of both the mines for the plan area have been wildlife habitat and watershed protection. Reclamation completed to date has created a land form and vegetation pattern resulting in re-establishment of the area as part of the home range of wildlife species including bighorn sheep, elk, mule deer and provincially threatened species such as grizzly bear and Athabasca rainbow trout. In addition to these threatened species, other wildlife species have re-colonised the reclaimed landscape (Bighorn, 2009). Following completion of coal mining, the disturbed lands are reclaimed, certified by the regulators, the MSL is cancelled and the lands revert back to the crown as vacant public land.

On both the Luscar and Gregg River mine sites public access was restricted on the active MSL. When the MSLs are returned to the Crown, access will no longer be restricted. As a result, it was deemed necessary to have a plan in place before the reclaimed lands revert back to the Crown to ensure appropriate land use and resource management.

This prompted ASRD, in collaboration with Teck Resources Ltd. (Teck) and Coal Valley Resources Inc. (CVRI), to take an integrated land management approach to commence an end-land-use planning initiative. The purpose of this land-use planning exercise is to provide direction and guidance for the future management of this public land.

\section{$2 \quad$ Plan area}

The plan area (Teck's Luscar Mine and CVRI's Gregg River Mine areas) is located along the front range of the Rocky Mountains, adjacent to Jasper National Park (Figure 1). The plan area is located in rugged terrain along the eastern slopes of the Nikanassin Range, part of the Front Range of the Rocky Mountains. Elevations within the mine footprint range from 1,500 to 2,075 metres above sea level.

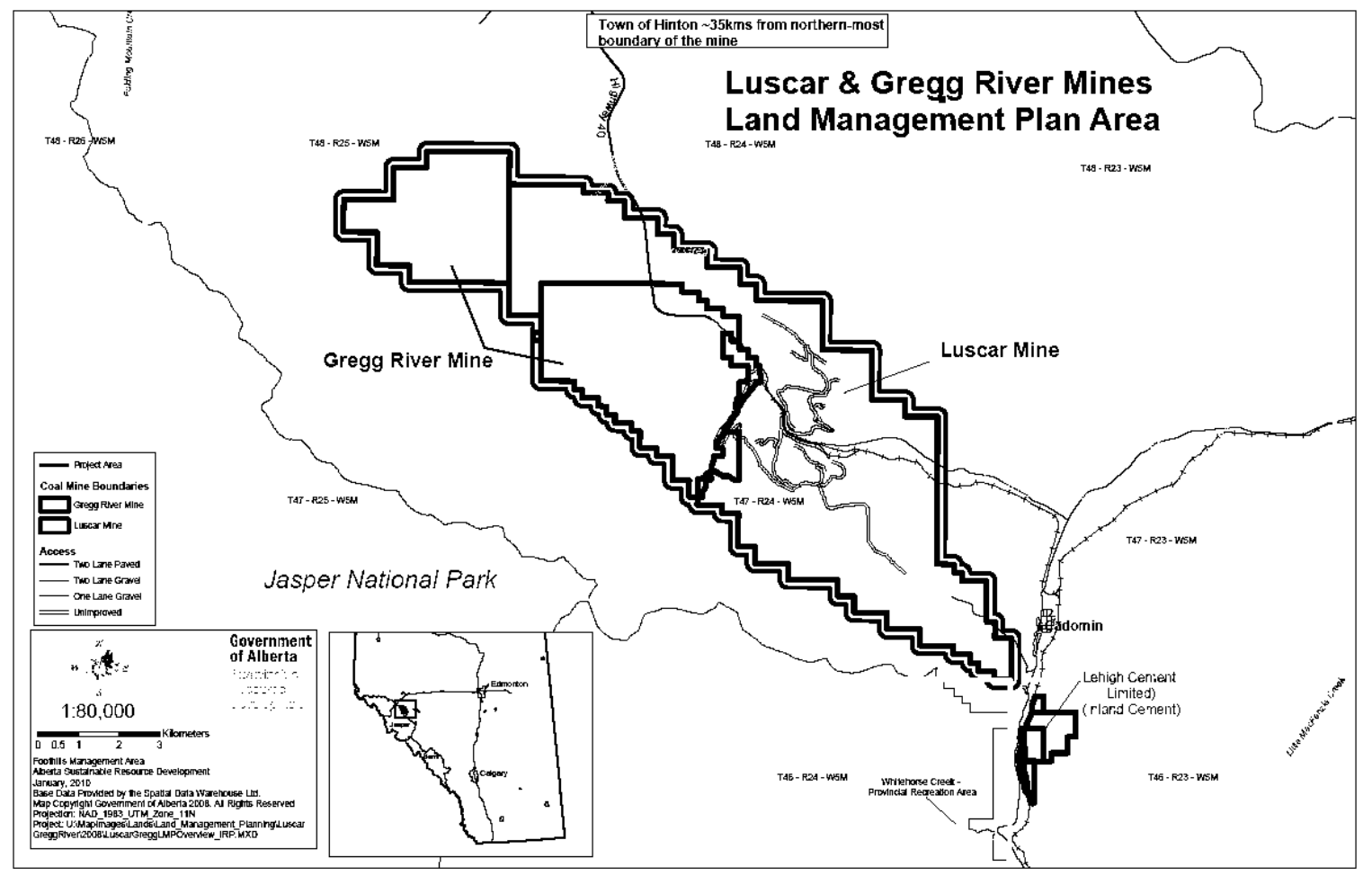




\section{Figure 1 Map of Luscar and Gregg River Mines land management plan area}

Prior to mine disturbance, the mine sites, primarily situated in the subalpine forests, consisted mainly of lodgepole pine (Pinus contorta Dougl. var. latifolia Engelm.) and Engelmann spruce (Picea engelmannii Parry ex Engelm.) cover, with patches of grasslands on ridge tops and steep south-facing slopes.

After mining and reclamation of the disturbed area the reclaimed areas have been seeded with a mixture of agronomic and native seeds to provide immediate watershed protection and wildlife habitat objectives. Large reclamation areas have been reforested with seedlings grown from native seed collected on the mine sites (Luscar \& Gregg, 2008). The total plan area includes disturbed areas, reclaimed areas, areas to be reclaimed and the certified area (Table 1). Reclaimed areas are defined as those areas where earthworks and seeding are completed, in some of these areas reforestation is ongoing.

Table 1 Total mine area, disturbed area, reclaimed area and certified area

\begin{tabular}{lcc}
\hline & $\begin{array}{c}\text { Gregg River Mine } \\
\text { (hectare) }\end{array}$ & $\begin{array}{c}\text { Luscar Mine } \\
\text { (hectare) }\end{array}$ \\
\hline Total area & $2,735.6$ & $4,381.6$ \\
Area disturbed & $1,252.2$ & $2,382.6$ \\
Area reclaimed & $1,252.2$ & $1,187.3$ \\
To be reclaimed & 0 & $1,195.3$ \\
Certified & 0 & 71.6 \\
\hline
\end{tabular}

Bighorn sheep, mule and white-tailed deer, moose and elk are commonly found on the reclaimed and adjacent landscapes (Bighorn, 2009). Chinook winds in winter expose the snow covered vegetation on the reclaimed landscape of the plan area to support high densities of bighorn sheep. Elk, which occupy deciduous and grass dominated lands, now use reclaimed mined areas. Porcupine, marmot, pica, squirrel, mink, marten, weasel and vole are small mammals that are frequently observed.

There has been a noticeable increase in the carnivore populations that prey on the herbivores found in the reclaimed areas. Black and grizzly bears, cougar, coyotes and wolves have become increasingly common due to the high density of prey. The adjacent unoccupied mountains are integral to Alberta's remaining grizzly bear ranges.

In the past, the presence of large bighorn sheep populations on the Luscar and Gregg River mines have provided opportunities to capture and relocate bighorn ewes to jurisdictions seeking to restore or augment existing bighorn populations. On the site, there are many wildlife-oriented recreational opportunities including wildlife viewing and photography. Currently, under the MSLs (Luscar and Gregg River mine areas), all hunting within the plan area is prohibited and public access is restricted. Hunting is a popular activity immediately adjacent to the border of the plan area.

\section{The planning process}

\subsection{The intent of the plan}

The intent of the land management plan (LMP) is to provide land and resource management direction for ongoing and future reclamation activities for the plan area. Furthermore, the plan will provide clarity regarding how the area may be accessed in future and what land uses may be considered compatible with the desired outcomes, including ensuring successful reclamation of the Luscar and Gregg River sites.

\subsection{Planning context}

Land and resource management direction for the planning area is currently provided by a variety of documents. Initial resource management direction was provided in the 1976 Coal Development Policy which zoned the mine lands as Category 4, permitting surface or underground mining subject to environmental 
protection and reclamation of the disturbed lands. This policy also confirms that future coal mining in the mines sites, if economical, could be continued. The 1990 Coal Branch Sub-Regional IRP provides broad management intent for the area, with the plan area located within the Mountain Park-Folding Mountain Resource Management Area. The management zones covering or adjacent to the plan area include prime protection, critical wildlife, general recreation and multiple use resource management areas.

The LMP provides a refinement to the direction provided in the IRP for the planning area, including greater clarity regarding land and resource management objectives. The 1999 Coal Branch Forest Land Use Zone (FLUZ) covers the planning area and provides a regulatory mechanism for access management, particularly recreation access. The LMP identifies opportunities to modify the FLUZ to ensure the necessary tools are in place to effectively manage the area.

The plan area is located entirely within the Yellowhead County and is, therefore, subject to municipal development permit approval for any proposed developments.

Throughout the planning process, elements such as legislation, regulatory requirements, existing land-use commitments, access management, recreational opportunities, conservation values and landscape capabilities of rehabilitated lands were considered.

\subsection{The process}

The project involved seven major stages including project initiation, data and information gathering, scenario development, draft LMP, LMP approval, LMP implementation and lastly, monitoring and evaluation. Public and stakeholder participation occurred concurrently with various stages of the project to ensure that the public, directly affected stakeholders and identified communities of interest (e.g. communities, industry, conservation, recreational users and traditional land users) had meaningful opportunities to influence the design and development of the LMP. Aboriginal communities were engaged in accordance with the GOA Aboriginal Consultation Guidelines.

Other organisations were engaged throughout the process, including: Foothills Research Institute; Alberta Tourism, Parks and Recreation staff; Jasper National Park representatives; and the local Member of Legislative Assembly (MLA).

\subsubsection{Project initiation}

In 2003, several stakeholders identified the need to initiate a planning process to provide direction for proper management of the reclaimed lands in the Luscar and Gregg River mines area.

In 2006, a working group was formed consisting of land managers and the coal companies. The group included ASRD, Yellowhead County, Teck, CVRI and AENV. Adjacent land managers, regulatory agencies and major public land stakeholders participated in the working group in an advisory capacity and included Jasper National Park, Energy Resources Conservation Board, Alberta Energy, Alberta Tourism Parks Recreation and Culture, and West Fraser. The MLA for West Yellowhead Constituency participated as an observer.

Key land-use challenges on the mine sites were identified including: wildlife management; motorised and non-motorised recreational use; and restoration and conservation of watershed and ecological systems.

\subsubsection{Data and information gathering}

Environmental data mapping and other information were gathered from provincial government departments, mining companies and research groups to develop a GIS map project for analysis and to develop map products for meetings and public and stakeholder information. Small individual stakeholder meetings and focus group meetings were organised to gather supporting data/information and feedback from key stakeholders to inform the development of the draft scenario and the LMP.

\subsubsection{Scenario development}

The scenario development stage started with formation of four focus groups having members with generally compatible view points. The focus groups consisted of representatives from: a wildland park stewardship 
group; environmental associations; residents from nearby communities; an Alberta naturalists association; municipalities; equestrian, local and provincial off highway vehicle (OHV) associations; a snowmobile club; professional outfitters associations; eco-tourism operators; an outfitter and a commercial operator; a trappers association; local and provincial fish and game associations; and the wild sheep hunters association.

The working group initially identified land-use issues, opportunities and constraints affecting the plan area. Small technical sub-groups from within the working group were formed to discuss specific issues and problems. The working group initially identified four broad land management scenarios to initiate and frame the discussion. The four management scenarios were as follows:

1. No change in action (base case).

2. Restoration and conservation of watershed and ecological system.

3. Balance between human use and resource conservation.

4. Maximum human use/influence.

Each scenario varied in both context and intensity of management actions and comprised a set of desired resource or future land management conditions. This suite of scenarios identified various combinations of land uses and resource management practices that would respond in varying degrees to the issues identified during the planning process.

The first activity for stakeholders was a field orientation program. The program was organised to give the focus group members first-hand knowledge of the plan area and identify issues (constraints and opportunities). This was followed by four individual focus group sessions organised to allow more focused discussion on the future of the Luscar and Gregg River mine sites. Each individual focus group session concentrated on one of the following four themes:

1. Conservation Group/Steward Group/Non-motorised recreation.

2. Motorised recreation (OHV group).

3. Commercial Operator/Outfitters/Tourism.

4. Hunting and wildlife management.

The participants of all four individual focus groups were brought together to discuss and exchange ideas. The specific purposes of the focus sessions were to: provide a forum for discussion regarding end land use; provide information on the land management planning process; generate input on the draft preferred scenarios; and identify other opportunities and constraints that could be considered for the preferred scenario and the land-use decision.

Three focus group sessions were conducted in March, April and August of 2009. The sessions focused on vision, goals, objectives and strategies. The groups also helped refine the definition of prohibited, restricted and permitted activities. Despite the diversity of interests, the participants were energetic, yet respectful of one another's values. Overall, the participants affirmed a vision that would see the continued protection of the habitats and populations of wildlife supported by the post-mining reclamation.

A draft vision was formulated by joint efforts of the working group and focus groups. The vision was subsequently refined and provided the basis for developing goals, objectives and strategies. To overcome the underlying criticism that the collaborative process has the propensity to develop second-best or vague outcomes, the group first agreed upon a vision statement for the plan area. Everything from this point on (scenario development, identifying goals, objectives and strategies) focused on this vision statement.

After review of the four scenarios by stakeholders, a draft preferred scenario was developed that tried to provide balance between managed human use and environmental resources conservation. The development of the preferred scenario was based on input generated and strategies deemed necessary for achieving the vision. The preferred scenario development process also developed a compatibility matrix identifying permitted, restricted and prohibited activities within the plan area. The draft preferred scenario was presented to the focus groups for further input and refinement. 
A public open house session was held on January 2010 to inform and solicit input on the draft preferred scenario for the development of the LMP. The focus group and the working group members were present as a resource for question/answer sessions. Information on all major issues, such as wildlife management and hunting, recreational opportunities, enforcement, education and communication, and stewardship opportunities, was displayed together with associated map products and photographs. A brief description of the outcome of this process is provided below. All content is still draft, and has not been approved by the Minister of Sustainable Resource Development. Vision: The plan will conserve wildlife and protect watersheds.

\subsubsection{Goals, objectives and strategies}

- Goal 1 - Wildlife and fishery resources and their habitats are healthy, productive and sustainable.

- Goal 2 - Water and watersheds are healthy, productive and sustainable.

- Goal 3 - Provide sustainable recreational opportunities.

- Goal 4 - Effective education and communication, enforcement, monitoring and evaluation, and stewardship.

- Goal 5 - Provide commercial and industrial opportunities compatible with the plan.

Under these five goals, 14 objectives were developed. Several strategies were then developed in order to achieve the stated vision, goals and objectives. The following strategies may be implemented after the lands receive reclamation certification, the MSL is cancelled and lands are returned to the crown and to SRD administration:

- The plan area will have a separate Wildlife Management Unit to reflect the uniqueness of the area (wildlife habitat and population).

- Maintain viable wildlife populations within the carrying capacity of their range.

- Wildlife management tools may include hunting, vegetation management and relocations.

- Modify Coal Branch Forest Land Use Zone boundaries.

- Create a wildlife viewing corridor sanctuary along Highway 40.

- Stocking of end pit lakes may be considered after reclamation certificates are issued.

- Biodiversity will be preserved through management of habitat for various terrestrial and aquatic biotic communities and by maintaining riparian buffers and wetlands.

- Management of recreational activities may include area access and seasonal timing restrictions.

- Five existing designated access trails (two motorised and three non-motorised) will remain.

- Camping is not allowed in the plan area.

- Industrial and commercial activities will be aligned with the direction provided by LMP.

- Agriculture leases - grazing of domestic animal/horses will not be allowed in the plan area due to the risk of disease transmission to wildlife species.

- Issuance of any sub-surface rights disposition will be aligned with the direction provided by the plan.

- There are coal resources in the area that have not been extracted. Coal companies will retain access to the coal resources. Any future coal mining activities will be aligned with the Plan.

The implementation of education and communication, enforcement, monitoring and evaluation, and stewardship strategies will be addressed in the development of a more detailed implementation plan. Research and interpretive opportunities may exist and be fostered within the plan area. 


\subsubsection{Draft land management plan}

A draft LMP was developed based on the preferred scenario put together jointly by the focus groups and the working group for restoration and conservation of watershed and ecological system and some human use. A final public review of the LMP will be held to solicit input on the LMP document.

\subsubsection{Plan approval and implementation}

The next step involves approval and implementation of the plan. A more detailed implementation plan to further articulate the strategies and to describe the roles and responsibilities associated with implementing the LMP will be developed. In particular, this will address education, communication, enforcement, monitoring and evaluation, and stewardship strategies.

The LMP will be reviewed and approved by SRD executive and implemented using a phased approach. Some of the recommended strategies may not be feasible under the current policy and regulatory framework and may be precedent-setting in nature. These may include: creating a new wildlife management unit to match the mine permit boundaries; defining wildlife management strategies; designation of highway corridor sanctuary and imposing restrictions on recreational activities. These recommendations may need further articulation and authorisation; however, they will provide a basis for any future policy and regulatory reforms.

Site-specific planning and stakeholder input will be considered as part of the LMP implementation process. Any future mine activities will reflect the intent of the LMP and provide mitigation measures where needed.

\subsubsection{Monitoring and evaluation}

A review of the LMP will take place in five years or sooner if information and the planning environment warrants. The review will address any required amendments based on new information.

\section{$4 \quad$ Lessons learnt}

The process has not yet resulted in a final plan approved by the GOA as a deliverable, but the process has provided an opportunity to make observations and gain insight for ongoing learning that could be applied to this project and future endeavours. The iterative nature of planning highlights that sometimes more gains may be realised from the process and relationship building than from the particular outcome of the plan as a deliverable.

\subsection{Strengths and opportunities}

Following are insights on perceived strengths of the process to date and opportunities that were capitalised on during the process. These were generated as a result of reflection by the authors of this paper and in response to what was heard from stakeholders throughout the process.

- The process generated dialogue amongst a diverse group of interested and affected parties that are not often engaged in a single collective forum.

- Participants showed a willingness and commitment to a process that defined long-term outcomes that some participants may not see brought to fruition due to the time horizon.

- The process improved knowledge amongst government, mining companies and the stakeholders.

- The process was successful in establishing a process to share data amongst government departments, mining companies and stakeholders.

- The forum was successful in generating several creative ideas.

- Some participants were very familiar with the area where as some were not. The field visit provided an opportunity for some to get familiar with the plan area and for others to contribute experience and knowledge of the area to the planning process.

- The process has improved relationships among government, mining companies and the stakeholders by initiating dialogue that did not previously exist. 
- The process developed trust among the stakeholders by involving them right at the beginning of the planning process.

- Participation of stakeholder members in all focus group sessions was excellent and very consistent considering the length of the process. Focus group members demonstrated real interest and commitment. Two additional sessions were organised on the request of the focus group members.

- This process, besides achieving agreement to the draft plan, also generated social capital benefits such as knowledge, improved relations and skills for all participants.

- The process was successful in creating more convergence amongst stakeholders on issues such as land designation, the use of hunting in wildlife management and level of recreational uses. Scenario planning played an important role in this process.

- The process provided the public with an opportunity to provide input during concept generation and the draft plan review.

\subsection{Challenges and opportunities for improvement}

Following are insights regarding challenges experienced at initiation and during the project and the resulting opportunities for enhancement and improvement for future projects. These were generated as a result of reflection by the authors of this paper and in response to what was heard from stakeholders throughout the process.

- There should be better articulation of legislation, requirements of the mining companies and reclamation requirements at the start of the process.

- More clarity on governance, at the outset, would allow better management of issues that are of a polarised nature (e.g. restricted access, land designation, hunting). Issues must be managed carefully and identified early so that consensus can be found successfully.

- There was some avoidance of starting the planning process in response to 'challenges'. This language was somewhat limiting from the start.

- Greater clarity regarding the planning process should be provided to the working group. The GOA needs to demonstrate stronger leadership in defining a process that would enable greater focus on content.

- Facilitation of process was required to move participants past discussion points that were previously concluded. Discussion regarding the same issues occurred repeatedly.

- Greater focus on documentation of rationale associated with the resulting objectives and strategies. The products developed did not always clearly link the vision to the strategies. This may create confusion and uncertainty in future for those not involved in the process and for those needing to implement the direction in future.

- The working group required a clearer definition of reporting protocols and roles for group members to ensure strong alignment of divisions within government departments as well as with other representatives. This created difficulty when attempting to bring the process to a close, with new concerns surfacing.

- Participants should be given more educational/information sessions at the beginning of the planning process.

- There were high cost in time and resources, as well as uncertainty regarding future resourcing needs and sourcing.

- There was inequality in influence, with some stakeholder groups receiving unfair advantage because of their degree of representation. 


\section{Discussions}

The Alberta government assures energy supply and benefits from energy and mineral resources development for Albertans. This needs to occur in a responsible, environmentally sustainable manner that supports GOA outcomes. Furthermore, the Alberta government is in the process of developing regional plans under the Land-use Framework initiative (Government of Alberta, 2008). The framework focuses on managing growth and sustaining a growing economy, while balancing it with social and environmental goals. This requires managing cumulative effects, developing strategies for conservation and stewardship and promoting efficient use of land to reduce the footprint of human activities. This Luscar and Gregg River Mines LMP provides needed direction and guidelines for protecting various values while addressing provincial outcomes at a local scale.

Coal companies are logically and legitimately concerned that lands retained in support of their resource development maintain their positive legacies; development of a land-use plan of this nature is important, timely and responsive. Unresolved liabilities can damage an industry's social license to operate and negate the constructive efforts of many contributors. Consequently, for coal companies it is important not only to assure that mining operations are conducted in an environmentally responsible manner, but also that reclamation achieves the re-establishment of healthy, robust, safe and self-sustaining landscapes. A key component of this is to promote and demonstrate viable long-term and diverse land uses under an appropriate land-use regime. From a mining company's perspective, a plan of this nature ensures clarity and certainty in terms of what, how and when various strategies are incorporated, both in the short- and long-term, in the management of these post-mine landscapes. Having a plan in place provides direction for future mine operations and reclamation, and also ensures that the reclamation work completed by the mining companies is sustainable well beyond the life of mine activity. This further demonstrates that mining activity is an interim and transitional land use.

Involvement of stakeholders, aboriginal groups and the public has been established as a much-needed component of a planning initiative. This is due to the increasing complexity of planning problems and understanding of the amount of knowledge/information available from within these groups. Involvement of the stakeholders has been instrumental in reducing conflicts and in providing general direction for the plan. The process was challenging due to differences of opinion and sometimes conflicting priorities however dialogue and communication at the initiation of the planning process helped overcome these conflicts. Collaboration resulting from forums, ranging from the mine site tour to the public open house, has been particularly beneficial. This collaboration has helped dispel perceptions, created a better understanding of constraints and allowed participants to explore and appreciate the opportunities that post-mine landscapes afford for biodiversity conservation and other land uses.

During all mine application and EIA review processes in Alberta, a conceptual end-land-use plan is provided by the proponent. This focuses on end uses for specific disturbed areas (pits and dumps) and is generally a description of proposed landform design and revegetation composition. The Luscar and Gregg River landuse planning provides a more holistic approach to end-land-use planning on a landscape level. This approach involves government agencies, mining companies and the stakeholders looking beyond the mining and reclamation activities, identifying the biodiversity and ecological values which exist on the post-mining landscape and assuring that a sustainable plan is established for their long-term conservation. The plan was meant to be realistic while addressing current and future management challenges. The plan will be endorsed by SRD, and the merit of the plan will be to ensure that the mining companies are supportive of the desired outcomes and the approach to enable success for implementation.

There is also alignment between the previously proposed post-mining land uses and the current use. There is likely higher stakeholder engagement now with the process and a better understanding by all regarding desired outcomes and future management challenges. The planning process set out to respect closure plans and be realistic in what could or could not change due to parameters such as legal requirements, cost and public safety. In future, the mines may seek to engage in land-use planning earlier on through a more engaged and collaborative process on desired outcomes.

SRD as the public land manager will be responsible for management of the lands following cancellation of the MSLs. The intent is that SRD will work with the stakeholders to implement the various strategies to meet the desired outcomes. 
The outcome of the land-use planning could provide new directions for reclamation and a rationale to do certain reclamation work differently than planned and approved within the scope of the existing regulatory framework. In some situations the reclamation scheme and technique may warrant modification from the approved reclamation practices and in some cases companies might target specific features (trails/roads, creek crossings, etc.) in order to align with the direction and guidelines provided by the land-use plan. Lastly, the plan would provide direction and guidelines for planning, operations and reclamation for new mining activities and may also be instrumental in creating circumstances for the involvement and commitment of the company beyond certification.

The lessons learnt in this planning initiative could be instrumental in providing a provincial policy direction for embarking on end-land-use planning for other coal mining areas. Coal mining companies have expressed interest and support for similar land-use planning initiatives. There could be several different approaches to address similar end-land-use issues/problems, but the approach used in this case is sustainable, responsive, fair and equitable and opens up dialogue amongst the government, coal mining companies and the stakeholders.

\section{Conclusion}

The process has provided an opportunity for collaboration among provincial and local government, industry, stakeholders and the public to explore opportunities to develop a more strategic and integrated land management approach to end-land-use planning. The planning initiative has been instrumental in creating a forum for various partners and the stakeholders to discuss several conflicting values, share and improve understandings, and come to an agreement on common management strategies.

This initiative also provides process guidance for developing end-land-use plans for other mining areas in the province in collaboration with other mining companies. The outcome of this process will both inform the development of the Upper Athabasca Regional Plan and will be reviewed following the completion of the regional plan to ensure alignment with the outcomes of that plan.

\section{References}

Bighorn Wildlife Technologies Ltd. (Bighorn) (2009) Cheviot and Luscar Mine Wildlife Inventory 2008, Prepared for Teck Coal Ltd., Canada, by Bighorn Wildlife Technologies Ltd., Hinton, 37 p.

Government of Alberta (2008) Land-Use Framework, Government of Alberta, Edmonton, 54 p.

Luscar and Gregg River Mines Land Management Plan Working Group (Luscar and Gregg) (2008) Luscar and Gregg River Mines Land Management Plan - Backgrounder for public circulation, Luscar and Gregg River Mines Land Management Plan Working Group, Hinton, $10 \mathrm{p}$.

Luscar and Gregg River Mines Land Management Plan Working Group (Luscar and Gregg) (2011) Luscar and Gregg River Mines Land Management Plan, Regional Integrated Decision, Luscar and Gregg River Mines Land Management Plan Working Group, Hinton, 23 p. 